Artículos

\title{
Influência das características organizacionais na evidenciação de diferentes categorias de custos ambientais*
}

Influence of organizational characteristics on the disclosure of different categories of environmental costs Influencia de las características organizacionales en la divulgación de diferentes categorías de costos ambientales

Viviane Krein ${ }^{\text {a }}$

Questor Sistemas Inteligentes, Brasil

DOI: https://doi.org/10.11144/Javeriana.cc20-50.icoe

vivianekrein@hotmail.com

ORCID: http://orcid.org/0000-0002-2768-6992

Recepção: 26 Janeiro 2019

Sirlene Koprowski

Aprovação: 29 Julho 2019

Universidade Comunitária da Região de Chapecó,

UNOCHAPECÓ, Brasil

ORCID: http://orcid.org//0000-0002-6661-2697

Antonio Zanin

Universidade Comunitária da Região de Chapecó,

UNOCHAPECÓ, Brasil

ORCID: http://orcid.org/0000-0001-7837-7375

Sady Mazzioni

Universidade Comunitária da Região de Chapecó,

UNOCHAPECÓ, Brasil

ORCID: http://orcid.org/0000-0002-8976-6699

Cristian Baú Dal Magro

Universidade Comunitária da Região de Chapecó,

UNOCHAPECÓ, Brasil

ORCID: http://orcid.org/0000-0002-7609-5806

\section{Resumo:}

O objetivo do artigo é analisar a influência das características organizacionais na evidenciação de diferentes categorias de custos ambientais nas empresas brasileiras de capital aberto listadas na bolsa de valores do Brasil (B3). Para determinar o nível de evidenciação dos custos ambientais adotou-se a fração entre as expressões-chave e a quantidade de páginas, constantes nos relatórios de sustentabilidade divulgados pelas organizações em questão, referentes a 2017. Os achados indicam que o nível médio de evidenciação de informações sobre custos ambientais das empresas pesquisadas é de $24,90 \%$. A categoria mais evidenciada é custos para controlar a ocorrência de impactos ambientais $(14,70 \%)$. Conclui-se que a característica de tamanho organizacional exerce influência positiva nos níveis de evidenciação em todas as categorias; pertencer ao Índice de Sustentabilidade Empresarial, ser internacionalizada e ter uma auditoria big four melhoram a evidenciação acima mencionada; enquanto níveis mais elevados de governança corporativa estão relacionados com uma menor evidenciação.

Código JEL: Q56.

Palavras-chave: características organizacionais, custos ambientais, empresas brasileiras.

\section{Abstract:}

The purpose of this paper is to analyze the influence of organizational characteristics on the disclosure of different categories of environmental costs in publicly traded Brazilian companies listed on the Brazilian stock exchange (B3). In order to determine the level of disclosure of environmental costs, the fraction between the key expressions and the number of pages in the sustainability reports issued by the organizations in question for 2017 was adopted. The findings indicate that the average level of disclosure of

\section{Autor notes:}

a Autora para correspondência. Correio eletrônico: vivianekrein@hotmail.com 
Information on environmental costs of the companies surveyed is $24.90 \%$. The most highlighted category is costs to control the occurrence of environmental impacts (14.70\%). It is concluded that the characteristic of organizational size has a positive infl uence on the levels of disclosure in all categories; belonging to the Corporate Sustainability Index, being internationalized and having a big four audit improve the above disclosure; while higher levels of corporate governance are related to lower disclosure. JEL Code: Q56.

Keywords: Organizational characteristics, environmental costs, Brazilian companies.

\section{Resumen:}

El objetivo del artículo es analizar la influencia de las características organizacionales en la divulgación de diferentes categorías de costos ambientales en las empresas brasileñas que cotizan en la bolsa de valores de Brasil (B3). Para determinar el nivel de divulgación de los costos ambientales se adoptó la fracción entre las expresiones clave y la cantidad de páginas, constantes en los informes de sostenibilidad divulgados por las organizaciones en cuestión para 2017. Los hallazgos indican que el nivel medio de divulgación de información sobre costos ambientales de las empresas seleccionadas es del 24,90\%. La categoría más divulgada es costos ambientales para controlar la ocurrencia de impactos ambientales (14,70\%). Se concluye que la característica de tamaño organizacional ejerce influencia positiva en los niveles de divulgación en todas las categorías; pertenecer al Índice de Sustentabilidad Empresarial, ser internacionalizada y tener una auditoría big four mejoran la divulgación; mientras que niveles más altos de gobierno corporativo están relacionados con niveles menores de evidencia de los costos ambientales.

Código JEL: Q56.

Palabras clave: características organizacionales, costos ambientales, empresas brasileñas.

\section{INTRODUÇÃO}

No decorrer dos últimos anos presenciam-se diversas mudanças no âmbito empresarial e social, resultado das pressões ocasionadas pela relação sociedade e natureza. Os avanços tecnológicos e da ciência, aliados ao interesse na exploração de recursos naturais como fonte inesgotável para fins lucrativos, proporcionam ao ser humano melhores condições de vida; entretanto, essa realidade tem influenciado negativamente o meio ambiente (Batista, Melo \& Carvalho, 2016). A incompatibilização do crescimento econômico e a preservação da natureza constitue-se como catalisadora de debates na sociedade e no meio acadêmico. Essas discussões sinalizam uma tomada de consciência a nível global para a temática (Leonardo, Abbas \& Bulla, 2013).

Neste contexto, a consciência ambiental tem favorecido a assunção de uma nova postura das organizações refletida na adoção de práticas mais sustentáveis. Além disso, tendo em vista que a evidenciação obrigatória exigida nas demonstrações contábeis não alcança a dimensão ambiental, passou a ocorrer uma cobrança por maior transparência. Porém, em resposta a estas expectativas, as empresas passaram a divulgar de forma voluntária informações de natureza ambiental (Rodrigues, Machado \& Cruz, 2011).

A evidenciação voluntária das informações ambientais, materializada no relatório de sustentabilidade, tem caráter qualitativo e quantitativo com o objetivo de demonstrar às partes interessadas as ações desenvolvidas pelas empresas nos projetos direcionados à preservação do meio ambiente. Dentre as razões para a evidenciação destacam-se a melhoria na reputação institucional, a redução no custo de capital, e uma maior liquidez no mercado acionário fruto da redução da assimetria informacional. Dessa forma, a responsabilidade ambiental constitui-se parte integrante da estratégia empresarial (Luca, Moura \& Nascimento, 2012).

Dentre as informações oferecidas às partes interessadas incluem-se os custos ambientais, devido à evolução da legislação ambiental e às exigências mercadológicas cada vez mais restritivas. As organizações passaram a destinar recursos com a finalidade de controle, preservação e recuperação ambiental (Rossato, Trindade \& Brondani, 2009). O adequado gerenciamento dos investimentos ambientais assegura a efi ciência e eficácia da organização para se perpetuar no longo prazo (Leonardo et al., 2013).

As pesquisas realizadas no âmbito dos custos ambientais abordaram a necessidade de identificar, reconhecer e evidenciar a forma com que as empresas interagem com o meio ambiente e necessitam de informações para melhorar a gestão e avaliação do desempenho (Rossato et al., 2009). Batista et al. (2016) constataram que os principais custos ambientais evidenciados pelas empresas do setor de mineração da Brasil, Bolsa, Balcão $\left(\mathrm{B}^{3}\right)$ estavam relacionados com certificados da gestão ambiental, multas, gastos com 
licenciamentos, processos e sanções, despesas com consumo de energia, uso da água, efluentes líquidos e resíduos sólidos. Contudo, a pesquisa revelou que os itens ambientais não foram divulgados de maneira suficiente para um aprofundamento analítico.

Fonseca, Machado, Costa e Souza (2016) analisaram a classificação e evidenciação dos custos ambientais em empresas integrantes do setor de papel e celulose constantes no Índice de Sustentabilidade Empresarial (ISE) entre 2010 e 2014, observando que as organizações apresentaram seus custos ambientais principalmente de forma qualitativa e positiva. $O$ estudo apontou uma evolução em relação a pesquisas anteriores que envolvem a análise da quantidade de divulgação dos custos ambientais. Silva, Cunha, Klann e Scarpin (2010) identificaram os custos ambientais das empresas que compóem o ISE e concluíram que as informações mais evidenciadas estão relacionadas aos custos para controlar os impactos ambientais.

Todavia, poucos estudos procuram investigar variadas características que tenham relação ou possam impactar especificamente o nível de evidenciação dos custos ambientais (Leal et al., 2017), sendo que pesquisas sobre a divulgação ambiental de forma geral, apontam para algumas características, a exemplo do tamanho e a participação na carteira ISE (Coelho, Ott, Pires \& Alves, 2013), ou o nível de impacto ambiental e a rentabilidade (Marquezan, Seibert, Bartz, Barbosa \& Alves, 2015).

Diante do exposto, considerando os indícios apontados para as dificuldades de identificação e mensuração dos custos ambientais, as falhas na divulgação, bem como diversas características empresariais que podem influenciar no repasse informacional sobre estes fatores, emerge a seguinte situação problema: Qual a influência das características organizacionais na evidenciação de diferentes categorias de custos ambientais nas empresas de capital aberto da $\mathrm{B}^{3}$ ? Desse modo, o objetivo do presente artigo é analisar a influência das características organizacionais na evidenciação de diferentes categorias de custos ambientais nas empresas de capital aberto da $\mathrm{B}^{3}$.

A justificativa permeia-se pelas evidências empíricas de que os custos ambientais podem representar 20\% ou mais do total dos custos operacionais de uma organização e, devido à complexidade na operacionalização pelos sistemas tradicionais de contabilidade, eles ficam ocultos em custos indiretos, o que dificulta a análise e a tomada de decisões corretas (Hansen \& Mowen, 2005). Por outro lado, o estudo considera a análise de um amplo conjunto de empresas de capital aberto da B3, diferentemente da maioria das pesquisas prévias que investigaram os custos ambientais de segmentos e setores específicos. Além disso, ao analisar o período mais recente disponível (2017), permitiu a comparação quanto à evolução na evidenciação e divulgação dos custos ambientais. Por fim, a pesquisa diferencia-se ao avaliar a influência de distintas características empresariais na evidenciação das categorias de custos ambientais.

Como contribuição teórica o estudo reforça que o tamanho da empresa, a participação na carteira ISE, a internacionalização das empresas e o fato de ter uma auditoria big four são características que podem influenciar numa maior evidenciação de informações sobre custos ambientais. No entanto, a presença da empresa em um nível diferenciado de governança corporativa pode provocar efeito inverso.

\section{REFERENCIAL TEÓRICO}

A literatura de suporte ao estudo contempla a evidenciação dos custos de cunho ambiental, as características organizacionais que podem impactar em sua divulgação e pesquisas anteriores direcionadas ao tema.

\section{Evidenciação de informações sobre custos ambientais}

A preocupação com as questões ambientais visa o direcionamento de limites na exploração dos recursos naturais, apontando os conflitos existentes entre o progresso econômico e o equilíbrio ecológico do planeta. Diante disso as organizações são pressionadas, seja pela sociedade ou pelos órgãos governamentais mediante 
restrições ou punições legais cada vez mais rigorosas, incentivando-as a adotar e incorporar políticas sustentáveis no planejamento estratégico para minimizar os impactos negativos ao meio ambiente e como forma de legitimação diante da comunidade (Durán \& Puglia, 2007).

A evolução da legislação ambiental estimula as empresas a repensarem sua conduta, porém, o cumprimento dessas exigências pode requerer desembolsos financeiros significativos e métodos adequados de gestão para manterem-se competitivas (Freitas, Pandolfo, Bordignon \& Kurek, 2007).

Em seus processos de controle e gestão estratégica, as organizações destinam maior atenção, estudo e análise àqueles custos expressivos, com a finalidade de melhorar a rentabilidade dos negócios, bem como sua continuidade (Rossato et al., 2009). Portanto, a identificação e mensuração dos custos ambientais devem estar em evidência no que tange à informação para a administração tomar suas decisões. Mas, avaliar e medir os custos ambientais tem esbarrado nas limitações dos instrumentos tradicionais da contabilidade. Em sua maioria e devido a sua natureza, esses custos são considerados como indiretos de fabricação ou fixos, o que prejudica a correta apropriação (Durán \& Puglia, 2007).

A literatura não apresenta uma definição clara e objetiva do que se designa como custos ambientais, sendo muitas vezes intangíveis, o que impossibilita sua identificação e reconhecimento (Grzebieluckas, Campos \& Selig, 2012). Admite-se que os custos de caráter ambiental devem compreender nomenclaturas que englobam os dispêndios financeiros, direta ou indiretamente, da operacionalização da gestão ambiental (Braga, 2007), representados pela soma dos custos dos recursos utilizados nas atividades voltadas ao controle, preservação e recuperação ambiental (Ribeiro, 1998).

Os custos ambientais originam-se pelo consumo de ativos ambientais; em contrapartida servem para a constituição dos passivos ambientais, uma vez que toda a ordem produtiva se caracteriza pelo uso de insumos que, ao serem submetidos ao processo de transformação, dão espaço aos produtos, subprodutos e resíduos. Assim a contabilidade, como principal fonte de informação, deve demonstrar os valores envolvidos e as medidas adotadas para a destinação dos resíduos, bem como os resultados alcançados na proteção e preservação ambiental de todo o processo (Rossato et al., 2009).

Os custos ambientais são abordados sob a ótica de duas dimensões: diretos e indiretos. Os diretos impactam na linha inferior da companhia, podem estar obscurecidos em outros custos ou despesas gerais mas contribuem na análise e gestão, resultando em melhor desempenho e benefícios para a organização (Fortes, 2002). Os indiretos não atingem diretamente a posição financeira da empresa, porém não podem ser ignorados, pois recaem sobre a sociedade como um todo e sobre as gerações futuras (Motta, 1996). Rover, Borba e Borgert (2008) também categorizaram os custos ambientais que vão desde desembolsos em domínios como prevenção, conservação, proteção ambiental ou gestão de resíduos, até indenizações e penalidades pelo não cumprimento das regulamentações legais do meio ambiente.

Diante das dificuldades em identificar, reconhecer, mensurar e categorizar os custos ambientais, além das características intrínsecas ao processo em que estão envolvidos, torna-se necessário estabelecer indicadores de desempenho ambiental, o que culmina na melhoria do desempenho econômico-ambiental das empresas. Dessa forma, a geração dos relatórios é um forte aliado na evidenciação desses indicadores (Fagundes, Vaz \& Hatakeyama, 2009). A divulgação dos relatórios contribui, adicionalmente, para as organizações legitimar-se perante a sociedade, pois tendem a estar mais propensas a agir e demonstrar suas ações ambientais (Marquezan et al., 2015).

Neste contexto recorreu-se aos estudos anteriores que abordam a evidenciação dos custos ambientais. Ricardo, Barcellos e Bortolon (2017) investigaram as variáveis que são capazes de influenciar na propensão de publicação do relatório de sustentabilidade ou relato integrado pelas empresas da B3, entre os anos de 2011 a 2014. Os resultados apontam que o tamanho e a participação na carteira do ISE impactam positivamente a probabilidade de publicação de um dos relatórios.

Chandok e Singh (2017) examinaram o ambiente corporativo nos websites e relatórios anuais das cem maiores empresas listadas na Bolsa de Bombaim no ano de 2014. Identificaram que a divulgação 
ambiental tem associação com alavancagem, tamanho e risco sistemático, enquanto a rentabilidade se mostrou inversamente proporcional.

Monteiro e Guzman (2010) analisaram os fatores que explicam a amplitude de 109 grandes empresas que operam em Portugal na divulgação das informações ambientais entre 2002 a 2004. Os resultados revelam que o nível de informação é baixo mas tem aumentado; da mesma forma o número de empresas nacionais que divulgam informações ambientais cresceu. Além disso, o tamanho e a listagem na bolsa de valores se mostraram positivamente relacionadas com a extensão da divulgação ambiental.

Os achados de Liu e Anbumozhi (2009) indicaram que as organizações chinesas que operam nas regióes costeiras orientais, onde a economia é relativamente desenvolvida, estão mais propensas a divulgar informações ambientais. Adicionalmente, encontraram que quanto melhor o desempenho econômico maior a divulgação das informações sobre investimentos ambientais e custos de controle da poluição.

Os resultados da pesquisa de Cormier, Magnan e Van Velthoven (2005) mostraram que o risco, a propriedade, os ativos fixos, o tamanho da empresa e a rotina são fatores determinantes para o nível de divulgação ambiental das grandes empresas da Alemanha, cujas preocupações ambientais são especialmente agudas sob um contexto legal e regulatório distinto. A partir da Teoria Institucional, sugerem que a evidenciação das empresas alemãs está convergindo ao longo do tempo impulsionada por forças complementares.

Raiborn, Butler e Massoud (2011) detectaram que, na tentativa de determinar a lucratividade, tomadores de decisões estão cada vez mais convencidos da importância de contabilizar e avaliar os riscos dos impactos ambientais, porém esbarram nos sistemas de contabilidade financeira. As razões subjacentes a essa divulgação incompleta são inúmeras e variam desde questões de mensuração até a estrutura do plano de contas da empresa, inclusive, comparam que as dificuldades se assemelham aos problemas enfrentados, ao se tentar determinar os custos da produção de produtos de baixa qualidade.

Gonçalves, Leonardo, Abbas, Okadi e Munhoz. (2014) constataram, em uma empresa brasileira que atua no setor de biocombustíveis, que os custos ambientais de preservação e restauração representam mais de $10 \%$ dos custos operacionais totais. No entanto, essas informações não são divulgadas e apresentadas nas demonstrações financeiras da organização.

Leal et al. (2017) verificaram que as empresas potencialmente poluidoras listadas na B3 em 2016 divulgaram pelo menos um dos itens de custos ambientais, demonstrando relação positiva com as variáveis de desempenho, liquidez e endividamento.

\section{Características organizacionais e a divulgação de custos ambientais}

Em virtude da revisão teórica, foram levantadas algumas características que podem influenciar o nível de evidenciação dos custos ambientais e sua direção:

a) Participação no ISE: partindo da premissa que as organizações participantes da carteira do ISE são reconhecidas e comprometidas com a responsabilidade ambiental e sustentabilidade empresarial, espera-se uma associação positiva no nível de divulgação dos custos ambientais. (Murcia, Fávero, Rover, Lima e Lima, 2008; Marquezan et al., 2015; Coelho et al., 2013; Ricardo et al., 2017).

b) Internacionalização: as empresas que possuem suas ações negociadas em mais de um mercado, principalmente em grandes mercados internacionais, precisam atender a um leque maior de informações devido à demanda exigida pela grande quantidade de usuários existentes nestes mercados, presumindo uma relação positiva com a divulgação dos custos ambientais (Coelho et al., 2013).

c) Nível governança corporativa: partindo do pressuposto de que a inclusão das organizações nos segmentos ocorre por adesão e considerando os princípios de transparência e prestação de contas da governança corporativa, espera-se uma maior divulgação de informações de cunho ambiental por parte das empresas dos estratos mais elevados (Coelho et al., 2013; Marquezan et al., 2015). 
d) Empresa de auditoria: o principal papel da auditoria é coibir comportamentos oportunistas, consequentemente empresas com grande reputação. Considerando que as "big four" possuem maior credibilidade e confiança no mercado, são menos propensas a se associar com clientes que divulgam baixos níveis de informação nos seus relatórios anuais, esperando-se uma associação positiva entre as variáveis (Murcia et al., 2008; Iatridis, 2013; Marquezan et al., 2015).

e) Tamanho: empresas maiores tendem a possuir maiores perdas pelo não reconhecimento de sua legitimidade pela sociedade. Além disso, conseguem absorver melhor os custos decorrentes do processo de divulgação, ensejando uma relação positiva com a evidenciação dos custos ambientais (Iatridis, 2013; Marquezan et al., 2015; Depoers \& Jéromê, 2017; Habib \& Bhuiyan, 2017; Chandok \& Singh, 2017).

f) Retorno sobre o ativo: espera-se uma associação positiva com a divulgação ambiental, tendo em vista que as organizações com maior rentabilidade tendem a divulgar mais informações com a finalidade de diferenciarse de seus concorrentes, devido à redução do risco e consequentemente diminuição do custo de capital e o aumento na liquidez das ações, fatores preponderantes para atrair novos investimentos (Coelho et al., 2013; Iatridis, 2013; Marquezan et al., 2015; Qiu, Shaukat \& Tharyan, 2016).

g) Liquidez geral da empresa: as organizações com maior liquidez estão mais propensas a um nível maior de divulgação dos custos ambientais, com o intuito de expandir seus negócios e solidificar os existentes; portanto espera-se uma associação positiva (Leal et al., 2017).

h) Endividamento geral: das empresas que possuem elevado grau de endividamento se espera um nível maior de divulgação de informações, com o objetivo de reduzir as incertezas de seus investidores (Coelho et al., 2013; Marquezan et al., 2015; Leal et al., 2017; Depoers \& Jéromê, 2017).

i) Ativos fixos: para reduzir ou eliminar os impactos causados ao meio ambiente, as empresas demandam de maiores investimentos em ativos fixos, associados positivamente com maior evidenciação dos custos ambientais (Cormier et al., 2005).

O pressuposto teórico reforça a relevância de mapear os fatores que despertam as organizações a evidenciar informações de caráter ambiental em seus relatórios anuais (Marquezan et al., 2015).

\section{PROCEDIMENTOS METODOLÓGICOS}

A pesquisa caracteriza-se com abordagem preponderantemente quantitativa, descritiva e documental. O nível de evidenciação dos custos ambientais foi construído a partir das informações constantes nos relatórios de sustentabilidade do ano de 2017, cuja pertinência de uso já fora apresentada por Rover, Borba e Murcia (2009) e Fonseca et al. (2016).

Primeiramente, realizou-se uma consulta no tópico "políticas socioambientais", constante nos Formulários de Referência, disponíveis no site da $\mathrm{B}^{3}$, das empresas de capital aberto com o intuito de identificar a declaração da companhia referente à divulgação do relatório de sustentabilidade para, posteriormente, realizar a coleta nos websites das empresas no período de 20 a 30 de junho de 2018.

A população da pesquisa correspondeu às empresas listadas na $\mathrm{B}^{3}$, exceto as pertencentes ao setor financeiro. A amostra foi composta por 246 empresas, considerando que foram excluídas as empresas com variáveis que resultaram em 5 desvios padrões da média e também aquelas que não dispuseram de todos os dados necessários para a consecução do objetivo da pesquisa. Destas, somente 66 companhias em oito setores econômicos da $\mathrm{B}^{3}$ (bens industriais: oito; consumo cíclico: nove; consumo não cíclico: seis; materiais básicos: oito; petróleo, gás e biocombustíveis: uma; saúde: uma; telecomunicações: três; utilidade pública: trinta), divulgaram os relatórios de sustentabilidade de 2017. Em decorrência da não obrigatoriedade, diversas empresas publicam seus relatórios somente no segundo semestre do ano seguinte (Almeida \& Santos, 2014), justificando a quantidade encontrada de relatórios de sustentabilidade neste período. 
Para mensurar o nível de evidenciação dos custos ambientais, procedeu-se à busca e quantificação de expressões ou palavras-chave para quatro diferentes categorias de custo. A escolha por esta metodologia foi com o objetivo de amenizar as interpretações subjetivas dos relatórios de sustentabilidade, devido à não padronização dos mesmos, e assim oferecer maior confiabilidade pois termos específicos fornecem os mesmos resultados pela repetição (Gamerschlag, Möller \& Verbeeten, 2011).

Foram definidos 80 termos, conforme as diretrizes de divulgação do Global Reporting Initiative (GRI), relacionados aos aspectos e indicadores ambientais e aos estudos de Rover et al. (2008), Marquezan et al. (2015), Viana e Crisótomo (2016), Batista et al. (2016), Viana e Crisótomo (2017); que auxiliaram na sustentação da escolha dos termos e na categorização dos custos ambientais. No tabela 1, são expostas as palavras e expressões utilizadas para cada categoria de custos ambientais:

TABELA 1

Categorias informações de custos ambientais e palavras-chave

\begin{tabular}{|c|c|}
\hline Categorias de custos ambientais & Palavras-chave de busca por categoria \\
\hline $\begin{array}{l}\text { 1. Custos ambientais para } \\
\text { controlar ocorrência de impactos } \\
\text { ambientais }\end{array}$ & $\begin{array}{l}\text { Água Reciclada e Reutilizada; Captação da água; Conservação } \\
\text { Ambiental; Consumo de Água; Consumo de Energia; Descarte de } \\
\text { Água; Efluentes; Ecoeficiência; Ecoeficiente; Eficiência do uso da } \\
\text { água; Eficiência Energética; Emissão de Gás; Emissão de } \\
\text { Poluentes; Energia Renovável; Energia Sustentável; Gases de } \\
\text { Efeito Estufa; Gestão Ambiental; Gestão de Resíduos; Impacto } \\
\text { Ambiental; Intensidade Energética; Irrigação; Poluição; } \\
\text { Preservação Ambiental; Prevenção Ambiental; Proteção ao Meio } \\
\text { Ambiente; Recursos hídricos; Resíduo Sólido; Resíduos } \\
\text { Transportados; Resíduos Tratados; Risco Ambiental; Tratamento } \\
\text { de Efluentes; Uso ou Consumo Sustentável. }\end{array}$ \\
\hline $\begin{array}{l}\text { 2. Custos de conservação em } \\
\text { atividades de pesquisa e } \\
\text { desenvolvimento }\end{array}$ & $\begin{array}{l}\text { Créditos de Carbono; Inovação sustentável; Logística Reversa; } \\
\text { Pesquisa e Desenvolvimento; Produtos Sustentáveis; Projeto de } \\
\text { Pesquisa; Tecnologia Limpa }\end{array}$ \\
\hline $\begin{array}{l}\text { 3. Custos ambientais em } \\
\text { atividades sociais }\end{array}$ & $\begin{array}{l}\text { Áreas de Prevenção Permanente (APP); Áreas Protegidas; } \\
\text { Biodiversidade; Educação Ambiental; Licenciamento Ambiental; } \\
\text { Obras de Melhoria; Reaproveitamento; Reciclagem; } \\
\text { Reflorestamento; Reserva Legal; Restauração Ambiental; Reuso; } \\
\text { Reutilização; }\end{array}$ \\
\hline $\begin{array}{l}\text { 4. Custos correspondentes a } \\
\text { danos ambientais }\end{array}$ & $\begin{array}{l}\text { Autuações; Contaminação; Dano Ambiental; Degradação; } \\
\text { Denúncia relacionada ao Meio Ambiente; Derramamento; } \\
\text { Indenizações; Multas; Passivo Ambiental; Punição; Queixas por } \\
\text { Impacto Ambiental; Reclamação Ambiental; Recuperação; } \\
\text { Sanções; Seguro Ambiental; Vazamento. }\end{array}$ \\
\hline
\end{tabular}

Fonte: adaptado de Rover et al. (2008).

A partir das palavras e expressões definidas e expostas no tabela 1, foram auferidas 7.481 observações dos relatórios de sustentabilidade das empresas pesquisadas. As expressóes custo(s) ambiental(is), gasto(s) ambiental(is), gasto(s) com meio ambiente, dispêndio(s) ambiental(is), desembolso(s) ambiental(is), investimento(s) ambiental(is), investimento em meio ambiente foram consideradas para as quatro categorias de custos ambientais e após a leitura classificaram-se de acordo com o enquadramento do respectivo grupo.

Outras palavras foram objeto de consulta nos relatórios, no entanto, não apresentaram resultado. As variações de número (singular e plural) e acentuação dos termos foram consideradas para dar maior credibilidade ao índice de evidenciação dos custos ambientais. Cabe ressaltar que algumas palavras podem resultar em dupla contagem, mas para atender ao escopo da pesquisa foi realizada a análise para identificar se o termo estava efetivamente referindo-se aos aspectos ambientais. Para minimizar o viés de interpretação e subjetividade, a coleta nos relatórios de sustentabilidade foi realizada por apenas um dos autores.

O índice total de evidenciação foi definido pela razão entre número total de palavras das categorias de custos ambientais pesquisadas e o número de páginas documento, repetindo o procedimento para cada uma das 
quatro categorias individualmente. Com o auxílio do software WordStat 8 foi possível a busca e quantificação das palavras-chave e o software FineCount contribuiu para designar o denominador da fração.

Para examinar a influência das características organizacionais na evidenciação dos custos ambientais, foram consideradas variáveis explicativas utilizadas em estudos anteriores assemelhados, conforme exposto no tabela 2.

TABELA 2A

Constructo da pesquisa

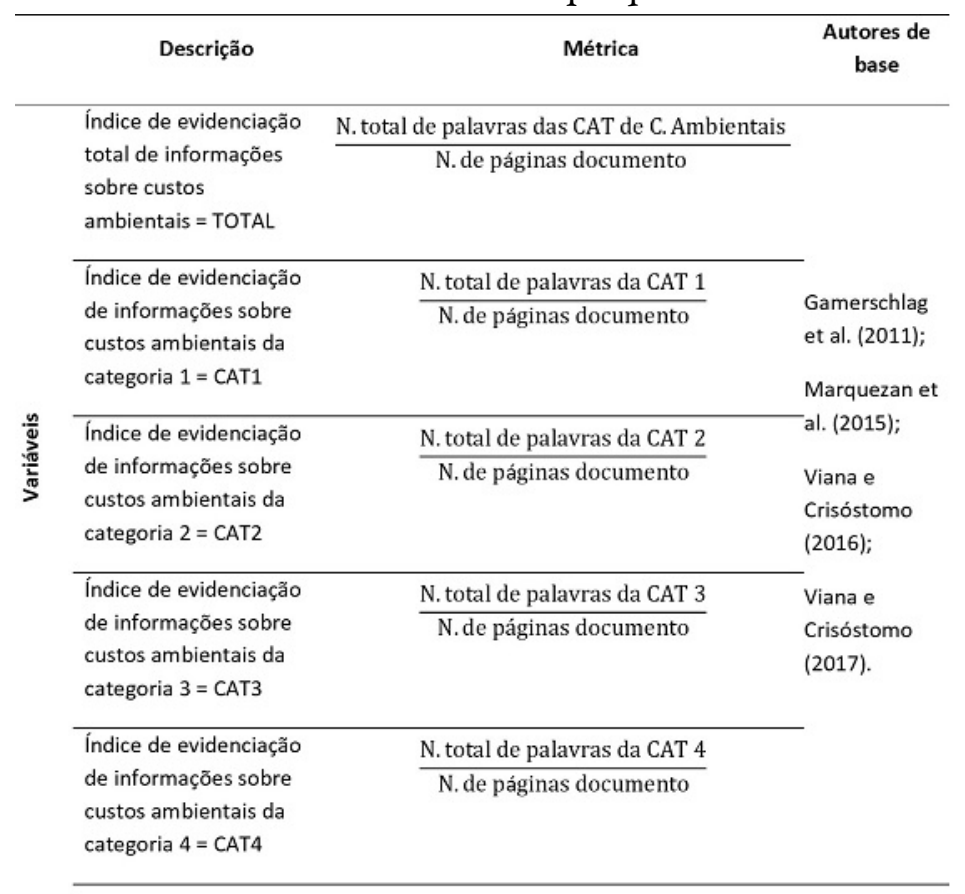

Fonte: elaborada pelos autores. 
TABELA 2B

Constructo da pesquisa

\begin{tabular}{|c|c|c|c|}
\hline & Descrição & Métrica & $\begin{array}{c}\text { Autores de } \\
\text { base }\end{array}$ \\
\hline \multirow{9}{*}{ 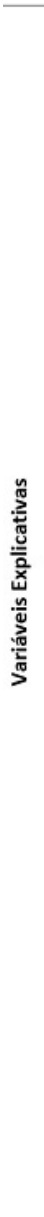 } & $\begin{array}{l}\text { Participação no ISE = } \\
\text { ISE }\end{array}$ & $\begin{array}{l}\text { Variável dummy, sendo } 1 \text { para } \\
\text { empresas pertencentes a carteira } \\
\text { ISE e } 0 \text { para as demais. }\end{array}$ & $\begin{array}{l}\text { Coelho et al. (2013); Ricardo } \\
\text { et al. (2017). }\end{array}$ \\
\hline & $\begin{array}{l}\text { Internacionalização = } \\
\text { INTER }\end{array}$ & $\begin{array}{l}\text { Variável dummy, sendo } 1 \text { para } \\
\text { empresas que estão listadas na } \\
\text { Bolsa de Valores de Nova York } \\
\text { (NYSE) e } 0 \text { para as demais. }\end{array}$ & Coelho et al. (2013). \\
\hline & $\begin{array}{l}\text { Nivel Governança } \\
\text { Corporativa }=\text { NGC }\end{array}$ & $\begin{array}{l}\text { Variável dummy, sendo } 1 \text { para } \\
\text { empresas em niveis diferenciados } \\
\text { de governança corporativa e } 0 \\
\text { para as demais. }\end{array}$ & $\begin{array}{l}\text { Coelho et al. (2013); } \\
\text { Marquezan et al. (2015). }\end{array}$ \\
\hline & $\begin{array}{l}\text { Empresa de auditoria = } \\
\text { AUD }\end{array}$ & $\begin{array}{l}\text { Variável dummy, sendo } 1 \text { para } \\
\text { empresa auditada por PWC, } \\
\text { KPMG, E\&Y ou D\&T, e } 0 \text { para as } \\
\text { demais. }\end{array}$ & $\begin{array}{l}\text { Murcia et al., (2008); latridis } \\
\text { (2013); Marquezan et al. } \\
\text { (2015). }\end{array}$ \\
\hline & $\begin{array}{l}\text { Tamanho da empresa } \\
=\text { TAM }\end{array}$ & Logaritmo natural do Ativo Total. & $\begin{array}{l}\text { latridis, (2013); Habib e } \\
\text { Bhuiyan, (2017); Chandok e } \\
\text { Singh (2017). }\end{array}$ \\
\hline & $\begin{array}{l}\text { Retorno sobre } 0 \text { ativo } \\
=\text { ROA }\end{array}$ & $\frac{\text { Lucro Líquido }}{\text { Ativo Total }}$ & $\begin{array}{l}\text { Qiu et al. (2016); Leal et al. } \\
\text { (2017); Habib e Bhuiyan } \\
\text { (2017). }\end{array}$ \\
\hline & $\begin{array}{l}\text { Liquidez geral } \\
=\mathrm{LIQ}\end{array}$ & $\frac{\text { Ativo C. + Ativo não C. }}{\text { Passivo C. + Exigivel a L. Prazo }}$ & $\begin{array}{l}\text { Assaf Neto (2006); Leal et al. } \\
\text { (2017). }\end{array}$ \\
\hline & $\begin{array}{l}\text { Endividamento geral = } \\
\text { ENDIV }\end{array}$ & $\frac{\text { Passivo Exigível Total }}{\text { Ativo Total }}$ & $\begin{array}{l}\text { Coelho et al. (2013); Leal et } \\
\text { al. (2017); Depoers e Jéromê } \\
\text { (2017). }\end{array}$ \\
\hline & $\begin{array}{l}\text { Ativos fixos } \\
=\text { ATFIX }\end{array}$ & $\frac{\text { Imobilizado }}{\text { Ativo Total }}$ & Cormier et al. (2005). \\
\hline
\end{tabular}

Fonte: elaborada pelos autores.

A fonte de dados para as variáveis dependentes foram os websites das empresas e o Economatica. Vale destacar que tanto as variáveis dependentes como as explicativas, expostas no tabela 2, foram determinadas e calculadas, considerando-se o ano de 2017. Assim, para analisar a influência das variáveis explicativas sobre as variáveis dependentes (índice de evidenciação de informações sobre custos ambientais, total e de cada categoria pesquisada), utilizaram-se os seguintes modelos de regressão:

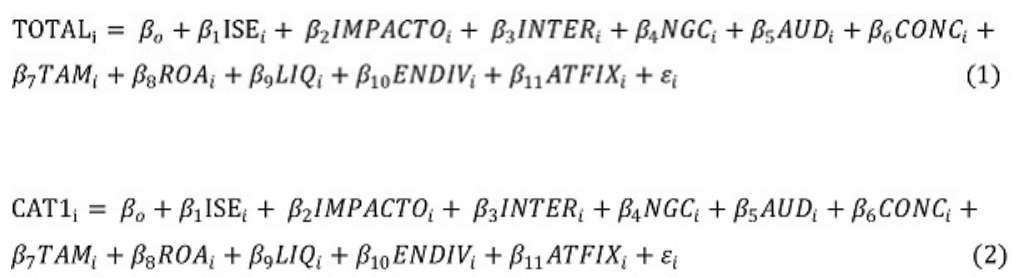




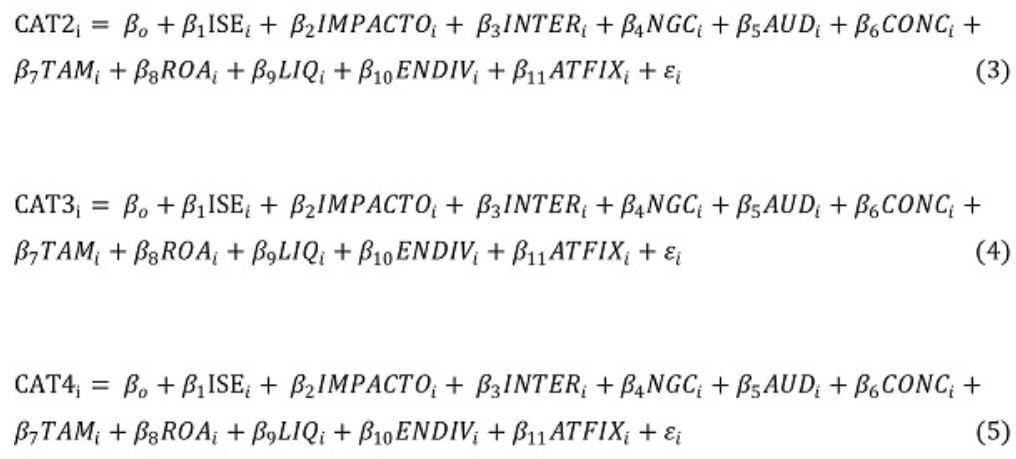

Para assegurar a confiabilidade dos resultados, buscou-se atender aos pressupostos do modelo de regressão linear múltipla. Nesse sentido, ao avaliar a multicolinearidade, utilizou-se o teste VIF; na auto correlação residual foi aplicado o teste de Durbin-Watson; na homocedasticidade o teste de White; e por fim, presumiuse pelo Teorema do Limite Central que as pesquisas com amostras superiores a 100 observações estão dispensadas de atentar a normalidade (Callegari-Jaques, 2003). Os dados foram analisados com uso do software Stata.

\section{DESCRIÇÃO DOS DADOS E ANÁLISE DOS RESULTADOS}

Nesta seção apresenta-se a descrição dos dados e análise dos resultados. Primeiramente, na tabela 3, expõe-se a estatística descritiva das variáveis analisadas. Quanto à evidenciação de informaçóes sobre custos ambientais vale destacar que, das 246 empresas que compõem a amostra do estudo, apenas 66 companhias divulgaram o relatório de sustentabilidade e o nível médio de divulgação total ficou em $24,90 \%$.

A categoria um (custos ambientais para controlar a ocorrência de impactos ambientais) apresentou maior nível médio de divulgação (14,70\%), resultado semelhante aos encontrados por Silva et al. (2010) e Rover et al. (2008). De outro modo, se diferencia do estudo de Batista et al. (2016), que constataram como principais itens ambientais divulgados as multas provisionadas, custos com licenciamentos, processos e sanções (categoria quatro desta pesquisa). Em seguida tem-se a categoria três (custos ambientais em atividades sociais), com evidenciação média de 6,90\%; categoria quatro (custos sobre danos ambientais), com média de $1,80 \%$; e por último, categoria dois (custos de conservação em atividades de pesquisa e desenvolvimento), com nível médio de divulgação de $1,40 \%$. 
TABELA 3

Estatística descritiva

\begin{tabular}{lccccc}
\hline & $\mathrm{N}$ & Mínimo & Máximo & Média & Desvio Padrão \\
\hline CAT1 & 246 & 0,000 & 1,552 & 0,147 & 0,291 \\
CAT2 & 246 & 0,000 & 0,237 & 0,014 & 0,034 \\
CAT3 & 246 & 0,000 & 1,056 & 0,069 & 0,152 \\
CAT4 & 246 & 0,000 & 0,473 & 0,018 & 0,051 \\
TOTAL & 246 & 0,000 & 2,807 & 0,249 & 0,496 \\
ISE & 246 & 0,000 & 1,000 & 0,107 & 0,309 \\
INTER & 246 & 0,000 & 1,000 & 0,063 & 0,243 \\
NGC & 246 & 0,000 & 1,000 & 0,526 & 0,500 \\
AUD & 246 & 0,000 & 1,000 & 0,783 & 0,413 \\
TAM & 246 & 3,3818 & 8,919 & 6,399 & 0,870 \\
ROA & 246 & 0,000 & 2,246 & 0,097 & 0,195 \\
LIQ & 246 & 0,107 & 9,972 & 1,867 & 1,288 \\
ENDIV & 246 & 0,100 & 9,383 & 0,803 & 0,823 \\
ATFIX & 246 & 0,000 & 0,871 & 0,242 & 0,225 \\
\hline
\end{tabular}

Fonte: dados da pesquisa.

Conforme apresentado na tabela 3, da amostra total do estudo (246 empresas), em média, 10,70\% das companhias fazem parte da carteira ISE (ISE); cerca de 6,30\% possui ações negociadas na Bolsa de Valores de Nova York (INTER); 52,60\% constam em níveis diferenciados de governança corporativa, sendo estes o Novo Mercado, Nível 1 e Nível 2 (NGC); e 78,30\% das empresas da amostra são auditadas por uma das auditorias Big four (AUD).

Na tabela 4 são apresentados os coeficientes de regressão, que permitem a análise da influência das variáveis explicativas selecionadas, sobre cada categoria e no nível total de evidenciação de informações sobre custos ambientais.

TABLE 4

Coeficientes das regressóes da influência de características organizacionais nos níveis de evidenciação dos custos ambientais

\begin{tabular}{lccccc}
\hline \multirow{2}{*}{ Variáveis } & \multicolumn{5}{c}{ Variáveis dependentes: Índices de Evidenciação } \\
& CAT1 & CAT2 & CAT3 & CAT4 & TOTAL \\
\hline (Constante) & $-0,692^{* * *}$ & $-0,093^{* * *}$ & $-0,291^{* * *}$ & $-0,086^{* * *}$ & $-1,162^{* * *}$ \\
ISE & $0,157^{* * *}$ & $0,018^{* * *}$ & 0,033 & $-0,011$ & $0,197^{* *}$ \\
INTER & 0,042 & $-0,009$ & 0,023 & $0,036^{* *}$ & 0,089 \\
NGC & $-0,075^{* *}$ & $-0,012^{* *}$ & $-0,033$ & $-0,001$ & $-0,120^{*}$ \\
AUD & 0,078 & 0,005 & $0,050^{*}$ & 0,009 & 0,143 \\
TAM & $0,120^{* * *}$ & $0,016^{* * *}$ & $0,049^{* * *}$ & $0,014^{* * *}$ & $0,199^{* * *}$ \\
ROA & 0,055 & 0,009 & $-0,004$ & 0,001 & 0,062 \\
LIQ & 0,002 & 0,001 & $-0,002$ & 0,0002 & 0,001 \\
ENDIV & 0,011 & 0,002 & 0,005 & 0,0013 & 0,019 \\
ATFIX & 0,056 & 0,007 & 0,069 & 0,019 & 0,151 \\
\hline R ${ }^{2}$ ajustado & 17,05 & 13,26 & 10,26 & 9,05 & 15,49 \\
F-ANOVA & $6,818^{* * *}$ & $5,16^{* * *}$ & $4,11^{* * *}$ & $3,71^{* * *}$ & $5,99^{* * *}$ \\
Durbin-Watson & 1,859 & 1,898 & 1,869 & 1,941 & 1,868 \\
Teste White & 0,0756 & 0,3150 & 0,8623 & 0,0711 & 0,0614 \\
VIF & 1,06 à 2,37 & 1,06 à 2,37 & 1,06 à 2,37 & 1,06 à 2,37 & 1,06 à 2,37 \\
\hline
\end{tabular}

Fonte: dados da pesquisa.

Conforme a tabela 4 , o $\mathrm{R}^{2}$ ajustado (percentual do poder explicativo do conjunto de variáveis independentes sobre mudanças na variável dependente) ficou em 15,49\% no modelo de evidenciação total, enquanto nas categorias um, dois, três e quatro, estes percentuais foram de 17,05\%, 13,26\%, 10,26\% e 
$9,5 \%$, respectivamente. Os testes F-ANOVA foram significantes ao nível de $1 \%$, ou seja, o conjunto de variáveis independentes exerce influência sobre as variáveis dependentes e os modelos são válidos para prever as mudanças nos níveis de evidenciação dos custos ambientais. Não foram identificados problemas de autocorrelação dos resíduos (teste Durbin-Watson) tampouco problemas de multicolinearidade (VIF) nem homocedasticidade pelo teste de White.

Quanto às variáveis explicativas, no modelo custos ambientais para controlar a ocorrência de impactos ambientais (CAT1), percebem-se coeficientes positivos nas variáveis TAM e ISE, significativos ao nível de $1 \%$, indicando que as empresas maiores e que participam da carteira ISE apresentaram maior nível de evidenciação.

Já a variável NGC apresentou coeficiente negativo e significativo ao nível de 5\%, influenciando de forma negativa o nível de evidenciação dos custos ambientais, contrariando os princípios de transparência e prestação de contas. Contudo, os resultados assemelham-se àqueles dos estudos de Santana, Góis, Luca e Vasconcelos (2015) e Bomfim, Teixeira e Monte (2014), que também evidenciaram relação negativa com a divulgação ambiental.

$\mathrm{Na}$ categoria custos de conservação em atividades de pesquisa e desenvolvimento (CAT2), novamente as variáveis TAM e ISE apresentaram coeficientes positivos e significativos ao nível de $1 \%$. No entanto, o fato da companhia pertencer a um nível diferenciado de governança corporativa (NGC) influenciou de forma negativa o nível de evidenciação de custos de conservação em atividades de pesquisa e desenvolvimento.

No caso do nível de evidenciação de informações sobre os custos ambientais em atividades sociais (CAT3), as variáveis TAM (1\%) e AUD (10\%) influenciaram de forma positiva no nível de evidenciação dos custos.

Para a evidenciação de custos correspondentes a danos ambientais (CAT4), o tamanho da empresa (TAM) e a internacionalização (INTER) apresentaram-se como fatores que influenciam positivamente o nível de divulgação. Estes resultados indicam que as empresas maiores e internacionalizadas apresentam maior preocupação com a divulgação de informações sobre danos ambientais, fator que pode ser explicado pelas exigências em nível global.

Quanto ao nível total de evidenciação dos custos ambientais (TOTAL), as variáveis que apresentaram coeficientes positivos e significativos foram TAM (1\%) e ISE (5\%). Os resultados estão alinhados com Murcia et al. (2008), Ricardo et al. (2017) e Coelho et al. (2013) para as variáveis tamanho e participação no ISE.

As variáveis referentes ao retorno sobre ativos (ROA), liquidez geral (LIQ), endividamento geral (ENDIV) e ativos fixos (ATFIX), não apresentaram coeficientes significativos em nenhuma categoria de evidenciação de custos ambientais, nem sobre o índice total de divulgação. No tabela 5 apresenta-se um resumo com as influências averiguadas das variáveis explicativas sobre o nível de evidenciação de informações sobre custos ambientais.

TABELA 5

Influências das características organizacionais para a evidenciação de custos ambientais

\begin{tabular}{|c|c|c|c|c|c|}
\hline \multirow{2}{*}{ Variáveis } & \multicolumn{5}{|c|}{ Variáveis dependentes: Índices de Evidenciação } \\
\hline & CAT1 & CAT2 & CAT3 & CAT4 & TOTAL \\
\hline $\begin{array}{l}\text { ISE } \\
\text { INTER }\end{array}$ & + & + & & + & + \\
\hline NGC & - & - & & & - \\
\hline AUD & & & + & & \\
\hline TAM & + & + & + & + & + \\
\hline
\end{tabular}

Fonte: dados da pesquisa.

Os resultados resumidos indicam que o tamanho da empresa exerceu influência positiva sobre todas as categorias de evidenciação de custos ambientais e sobre o índice total. Os achados corroboram as evidências empíricas prévias e reforçam a concepção da Teoria da Legitimidade, ou seja, que para legitimar-se as empresas atuam a partir de valores, princípios e padrões morais e éticos aceitos, e sua não conformidade pode ameaçar 
a imagem e a reputação (Marquezan et al., 2015). As empresas maiores, por serem mais visíveis, estão mais propensas a terem impactos financeiros negativos e significativos pela rejeição da sociedade. Outra possível explicação é que as empresas maiores conseguem absorver melhor os custos envolvidos na divulgação (Coelho et al., 2013).

Especificamente em relação às categorias de custos ambientais para controlar ocorrência de impactos ambientais (CAT1) e custos de conservação em atividades de pesquisa e desenvolvimento (CAT2), notamse influências positivas da participação na carteira ISE, ao passo que o fato da companhia constar em um nível diferenciado de governança corporativa, exerce uma influência negativa sobre o nível informacional. Portanto, pode-se inferir que empresas pertencentes à carteira ISE tendem a divulgar mais informaçóes sobre estas duas categorias de custos, enquanto as que constam em níveis diferenciados de governança corporativa, tendem a evidenciar menos. O ISE é uma carteira constituída por ações de empresas reconhecidas e comprometidas com a responsabilidade social e sustentabilidade empresarial a partir de critérios bem definidos pela $\mathrm{B}^{3}$ (Coelho et al., 2013), justificando os resultados encontrados conforme esperado.

Ademais, afirma-se que o ambiente institucional introduz barreiras ao pleno desenvolvimento do mercado de ações brasileiro e isso pode explicar o impacto negativo das práticas de governança corporativa sobre o nível de evidenciação dos custos ambientais (Mazzioni, Cofsevicz, Moura, Macêdo \& Kruger, 2017).

$\mathrm{O}$ fato de a empresa ser auditada por uma auditoria big four mostrou-se fator de influência positiva sobre o nível de evidenciação de custos ambientais em atividades sociais (CAT3). Ao avaliar o fator auditoria, Murcia et al. (2008) ressaltam que as empresas de auditoria tendem a influenciar seus clientes a evidenciar o máximo de informação possível, logo, as consideradas big four tendem a exigir padrões mais elevados de evidenciação de seus clientes, fato que pode explicar os resultados encontrados.

Por fim, os resultados apontam que as empresas internacionalizadas influenciam positivamente a evidenciação de custos ambientais atrelados aos danos ambientais. Esse achado sugere que as empresas com ações negociadas em mais de um mercado precisam atender diversos stakeholders e tal demanda exige maior quantidade de informações voluntárias, corroborando os achados de Coelho et al. (2013).

\section{CONSIDERAÇÕES FINAIS}

Os resultados do estudo indicaram que o nível médio de evidenciação de informações sobre custos ambientais divulgadas nos relatórios de sustentabilidade das empresas pesquisadas foi de aproximadamente 24,90\%. Quanto às quatro categorias de custos ambientais, adotadas com base no estudo de Rover et al. (2008), a que apresentou maior nível médio de divulgação refere-se aos custos ambientais para controlar a ocorrência de impactos ambientais.

Atendendo ao intuito principal da pesquisa, testaram-se diversas características organizacionais e as que exerceram influência sobre o nível de evidenciação dos custos ambientais foram: participação no ISE, internacionalização, nível de governança corporativa, tipo da empresa de auditoria e tamanho da companhia. O destaque foi para o tamanho da empresa, apresentando influência positiva em todas as categorias de custos analisadas. Dessa forma, pode-se dizer que empresas maiores apresentam níveis de divulgação mais elevados referente aos custos ambientais, possivelmente em decorrência de sua maior visibilidade e cobrança da sociedade por uma postura correta e ética em relação ao meio ambiente.

A participação na carteira ISE apresentou influência positiva sobre a evidenciação de custos ambientais para controlar ocorrência de impactos ambientais e custos de conservação em atividades de pesquisa e desenvolvimento. Por sua vez, empresas internacionalizadas exerceram influência positiva sobre a evidenciação custos correspondentes aos danos ambientais e o tipo de empresa de auditoria sobre a evidenciação de custos ambientais em atividades sociais. De maneira abrangente, pode-se considerar que os custos ambientais para controlar ocorrência de impactos ambientais, custos de conservação em atividades de 
pesquisa e desenvolvimento e custos ambientais em atividades sociais referem-se aos aspectos positivos quanto à postura da empresa frente aos seus custos ambientais. Portanto, percebe-se a preocupação das empresas constantes no ISE e auditadas por big four em evidenciar tais aspectos. O efeito contrário é observado na variável referente aos níveis diferenciados de governança corporativa, sobre a evidenciação de custos ambientais das categorias um e dois. Para este achado, indícios na literatura apontam que características do mercado brasileiro de ações e do próprio ambiente institucional podem estar reduzindo o impacto positivo esperado de boas práticas de governança corporativa sobre o repasse informacional, especificamente de custos ambientais.

O presente estudo apresenta contribuições empíricas, indicando características organizacionais que possuem capacidade de influenciar a evidenciação de informações sobre distintas categorias de custos ambientais, sem considerar um setor específico de atuação, como a abordagem percebida em estudos anteriores.

No entanto, são percebidas algumas limitações na pesquisa, como a análise de período único. Uma análise temporal maior pode conduzir a outros resultados mais robustos. Para futuras investigações, sugere-se ampliar o período de análise e a consideração de outras características organizacionais que possam influenciar no nível de evidenciação.

\section{Agradecimentos}

As autoras Viviane Krein e Sirlene Koprowski agradecem a Universidade da Região de Chapecó, UNOCHAPECÓ, e Programa de Suporte à Pós-Graduação de Instituições Comunitárias de Educação Superior (PROSUC) - Coordenação de Aperfeiçoamento de Pessoal de Nível Superior (CAPES), pela bolsa de estudos que possibilitou a realização da pesquisa.

\section{Referências}

Almeida, M. A., \& Santos, J. F. D. (2014). Disclosure voluntário de responsabilidade social corporativa das empresas listadas na BM\&FBovespa. Revista de Gestão Social e Ambiental, 8(3), 69-88. http://10.5773/rgsa.v8i3.925

Batista, K. R., Melo, J. F., \& Carvalho, J. R. (2016). Evidenciação dos itens ambientais nas empresas do setor de mineração de metálicos cadastradas na BM\&FBOVESPA. Revista de Gestão Ambiental e Sustentabilidade, 5(1), 128-143. http:// 10.5585/geas.v5i1.296

Bomfim, E. T., Teixeira, W. D., \& Monte, P. A. (2015). Relação entre o disclosure da sustentabilidade com a governança corporativa: um estudo nas empresas listadas no Ibrx100. Sociedade, Contabilidade e Gestão, 10(1), 6-28. http://10.21446/scg_ufrj.v10i1.13341

Braga, C. (2007). Contabilidade ambiental: ferramenta para a gestão da sustentabilidade. Atlas, São Paulo, Brasil.

Callegari-Jaques, S. M. (2003). Distribuição qui-quadrado. Bioestatística: princípios e aplicações. Porto Alegre: Artmed.

Chandok, R. I., \& Singh, S. (2017). Empirical study on determinants of environmental disclosure: Approach of selected conglomerates. Managerial Auditing Journal, 32(4-5), 332-355. https://doi.org/10.1108/MAJ-03-2016-1344

Coelho, F. Q., Ott, E., Pires, C. B., \& Alves, T. W. (2013). Uma análise dos fatores diferenciadores na divulgação de informações voluntárias sobre o meio ambiente. Contabilidade Vista \& Revista, 24(1), 112-130.

Cormier, D., Magnan, M., \& Van Velthoven, B. (2005). Environmental disclosure quality in large German companies: economic incentives, public pressures or institutional conditions? European accounting review, 14(1), 3-39.

Durán, O., \& Puglia, V. B. (2007). Scorecard ambiental: monitoração dos custos ambientais através da web. Ingeniare. Revista Chilena de Ingeniería, 15(3), 291-301. http://dx.doi.org/10.4067/S0718-33052007000300009

Fagundes, A. B., Vaz, C. R., \& Hatakeyama, K. (2009). A relação entre os custos e receitas ambientais como principal indicador do desempenho econômico-ambiental das organizações. Revista Produção Online, 9(3), 442-465. https://doi.org/10.14488/1676-1901.v9i3.177 
Fonseca, D., Machado, D. G., Costa, A. A., \& Souza, M. A. (2016). Evolução da evidenciação de custos ambientais: um estudo em empresas do setor de papel e celulose - integrantes do Índice de Sustentabilidade Empresarial - ISE. Revista de Gestão Ambiental e Sustentabilidade, 5(2), 34-48. http://10.5585/geas.v5i2.403

Fortes, H. (2002). The need for environmental reporting by companies. Greener Management International, 40(1), 77-92.

Freitas, J. L., Pandolfo, A., Bordignon, S., \& Kurek, C. (2017, dezembro). Custo ambiental: uma abordagem sobre o conceito e sua aplicação em uma indústria no processo de microfusão de aço. Anais do Congresso Brasileiro de Custos, João Pessoa, PB, Brasil, 14.

Gamerschlag, R., Möller, K., \& Verbeeten, F. (2011). Determinants of voluntary CSR disclosure: empirical evidence from Germany. Review of Managerial Science, 5(2-3), 233-262. https://doi.org/10.1007/s11846-010-0052-3

Gonçalves, M. N., Leonardo, V. S., Abbas, K., Okadi, K. L., \& Munhoz, T.R. (2014). Expenditures results for the control of environmental impacts activity in sugarcane: identification, representativeness and disclosure. Custos e Agronegócio on line, 10(4), 345-368.

Grzebieluckas, C., Campos, L. M., \& Selig, P. M. (2012). Contabilidade e custos ambientais: um levantamento da produção científica no período de 1996 a 2007. Produção, 22(2), 322-332. http://dx.doi.org/10.1590/ S0103-65132011005000054

Hansen, D. R., \& Mowen, M. M. (2005). Environmental cost management. Management accounting, 7, 490-526.

Leal, P. H., Almeida, J. E. G. S., Feitosa, M. O., Almeida, T. A., Gusmão, C. R., \& Pereira, R. S (2017, novembro). Disclosure de custos ambientais nas empresas potencialmente poluidoras listadas na BM\&FBovespa. Anais do Congresso Brasileiro de Custos, Florianópolis, SC, Brasil, 24.

Leonardo, V.S., Abbas, K., \& Bulla, P. R. (2013). Sistema de gestão ambiental como suporte na identificação dos custos com controle, preservação e recuperação do meio ambiente. Enfoque Reflexão Contábil, 32(3), 129-149. http:// $10.4025 /$ enfoque.v32i3.21729

Liu, X., \& Anbumozhi, V. (2009). Determinant factors of corporate environmental information disclosure: an empirical study of Chinese listed companies. Journal of cleaner production, 17(6), 593-600. http://10.1016/ j.jclepro.2008.10.001

Luca, M. M., Moura, A. A., \& Nascimento, F. S. (2012). Evidenciação voluntária de informações sociais por empresas de capital aberto no Brasil com base nos indicadores de responsabilidade social da ONU. Revista Alcance, 19(3), 362-380. http://dx.doi.org/10.14210/alcance.v19n3.p362-380

Marquezan, L. H., Seibert, R. M., Bartz, D., Barbosa, M. A., \& Alves, T. W. (2015). Análise dos determinantes do disclosure verde em relatórios anuais de empresas listadas na BM\&FBovespa. Contabilidade, Gestão e Governança, $18(1), 127-150$.

Mazzioni, S., Cofsevicz, C. M., Moura, G. D., Macêdo, F. F., \& Kruger, S. D. (2017). Influência da governança corporativa na evidenciação voluntária de informações de natureza socioambiental. Revista Organizações em Contexto, 13(26), 311-338. http://dx.doi.org/10.15603/1982-8756/roc.v13n26p311-338

Monteiro, S. M. S., \& Guzmán, B. A. (2010). Determinants of environmental disclosure in the annual reports of large companies operating in Portugal. Corporate Social Responsibility and Environmental Management, 17(4), 185-204. https://doi.org/10.1002/csr.197

Motta, R. S. (2006). Indicadores Ambientais no Brasil: aspectos ecológicos, de eficiência e distributivos. IPEA, Rio de Janeiro, Brasil.

Murcia, F. D., Fávero, L. P., Rover, S., Lima, G. A., \& Lima, I. (2008). 'Disclosure Verde' nas demonstrações contábeis: características da informação ambiental e possíveis explicações para a divulgação voluntária. Contabilidade, Gestão e Governança, 11(1-2), 260-278.

Qiu, Y., Shaukat, A., \& Tharyan, R. (2016). Environmental and social disclosures: Link with corporate financial performance. The British Accounting Review, 48(1), 102-116. http://10.1016/j.bar.2014.10.007

Raiborn, C. A., Butler, J. B., \& Massoud, M. F. (2011). Environmental reporting: toward enhanced information quality. Business Horizons, 54(5), 425-433. http://10.1016/j.bushor.2011.04.004 
Ribeiro, M. (1998). O custeio por atividades aplicado aos gastos de natureza ambiental. Caderno de Estudos FIFECAFI, 10(19), 82-91. http://dx.doi.org/10.1590/S1413-92511998000300007

Ricardo, V. S., Barcellos, S. S., \& Bortolon, P. M. (2017). Relatório de sustentabilidade ou relato integrado das empresas listadas na BM\&FBovespa: fatores determinantes de divulgação. Revista de Gestão Social e Ambiental, 11(1), 90-104. http://dx.doi.org/10.24857/rgsa.v11i1.1233

Rodrigues, J. M., Machado, D. G., \& Cruz, A. P. C. (2011). Evidenciação de custos ambientais em empresas do segmento de adubos e fertilizantes. Revista Contemporânea de Contabilidade, 8(15), 63-86. http://10.5007/2175-8069.2011v8n15p63

Rossato, M. V., Trindade, L. L., \& Brondani, G. (2009). Custos ambientais: um enfoque para a sua identificação, reconhecimento e evidenciação. Revista Universo Contábil, 5(1), 72-87.

Rover, S., Borba, J. A., \& Borgert, A. (2008). Como as empresas classificadas no Índice de Sustentabilidade Empresarial (ISE) evidenciam os custos e investimentos ambientais? Revista Custos e agronegócio on line, 4(1), 2-25.

Rover, S., Borba, J. A., \& Murcia, F. D. (2009). Características do disclosure ambiental de empresas brasileiras potencialmente poluidoras: Análise das demonstrações financeiras e dos relatórios de sustentabilidade do período de 2005 a 2007. Contextus - Revista Contemporânea de Economia e Gestão, 7(1), 23-36. http:// dx.doi.org/10.19094/contextus.v7i1.32101

Santana, L. M., Góis, A. D., Luca, M. M., \& Vasconcelos, A. C. (2015). Relação entre disclosure socioambiental, práticas de governança corporativa e desempenho empresarial. Revista Organizações em Contexto, 11(21), 49-72. http:// dx.doi.org/10.15603/1982-8756/roc.v11n21p49-72

Silva, J. O., Cunha, P. R., Klann, R. C., \& Scarpin, J. E. (2010). Evidenciação dos custos ambientais nas empresas que compõem o índice de sustentabilidade empresarial (ISE). Revista Contemporânea de Contabilidade, 7(14), 159-182. http://10.5007/2175-8069.2010v7n14p159

Viana, D. B. C. Jr., \& Crisóstomo, V. L. (2016). Nível de disclosure ambiental das empresas pertencentes aos setores potencialmente agressivos ao meio ambiente. Contabilidade, Gestão e Governança, 19(2), 254-273. http:// dx.doi.org/10.21714/1984-3925_2016v19n2a5

Viana, D. B. C. Jr., \& Crisóstomo, V. L. (2017). Nível de disclosure socioambiental: uma análise comparativa entre empresas brasileiras de acordo com o potencial de agressão ao meio ambiente. Revista de Administração da UFSM, 10, 79-99. http://dx.doi.org/10.5902/1983465925301

\section{Notas}

* Artigo de pesquisa científica e tecnológica.

Licencia Creative Commons CC BY 4.0 